\title{
Exigência de fósforo disponível para tilápia-do-nilo (35 a 100 g)
}

\section{Wilson Massamitu Furuya ${ }^{1}$, Keila Michele Fujii ${ }^{2}$, Lilian Dena dos Santos ${ }^{3}$, Tarcila Souza de Castro Silva ${ }^{3}$, Lilian Carolina Rosa da Silva ${ }^{3}$, Mariana Michelato ${ }^{2}$}

\author{
${ }^{1}$ Departamento de Zootecnia, UEM, Av. Colombo, 5790, CEP: 87020-900, Maringá-PR. \\ 2 Curso de graduação em Zootecnia - UEM, Maringá-PR. \\ 3 Programa de Pós-graduação em Zootecnia - UEM, Maringá-PR.
}

\begin{abstract}
RESUMO - Objetivou-se determinar a exigência de fósforo disponível para tilápias-do-nilo. Utilizaram-se 144 peixes com peso vivo inicial de 35,33 \pm 0,66 g, distribuídos em delineamento de blocos ao acaso, com quatro tratamentos e três repetições. Foram fornecidas dietas com 29,0\% PB, $2.980 \mathrm{kcal} / \mathrm{kg}$ de energia digestível (ED) e quatro níveis de fósforo disponível $(0,25 ; 0,35 ; 0,45$ ou 0,55\%), obtidos pela utilização de fosfato bicálcico como fonte de fósforo. As dietas foram fornecidas aos peixes três vezes por dia, até aparente saciedade, durante 46 dias. Não foi observado efeito dos níveis de fósforo disponível na dieta sobre o índice hepatossomático, a taxa de sobrevivência e os teores de água e proteína bruta na carcaça. O aumento dos níveis de fósforo disponível na dieta promoveu aumento linear do ganho de peso médio, da excreção de fósforo e dos teores de cinza na carcaça e de cinzas, cálcio e fósforo nos ossos. Houve efeito quadrático dos níveis de fósforo disponível sobre o consumo de ração, a conversão alimentar e a taxa de eficiência protéica, que foram melhores nos níveis 0,37 ; 0,48 e 0,48\% de fósforo disponível, respectivamente. A exigência de fósforo disponível para tilápia-do-nilo de 35 a 100 g é de $0,48 \%$ (0,53\% na matéria seca).
\end{abstract}

Palavras-chave: desempenho, mineral, ossos, peixe

\section{Available phosphorus requirement of Nile tilapia (35 to $100 \mathrm{~g}$ )}

\begin{abstract}
The objective of this work was to determine the available phosphorus requirement of Nile tilapia. A total of 144 fishes with initial weight $35.33 \pm 0,66 \mathrm{~g}$ LW were distributed to a completely randomized blocks design, with four treatments and three replicates. Diets with $29.0 \% \mathrm{CP}$ and $2980 \mathrm{kcal} / \mathrm{kg} \mathrm{DE}$ and four available phosphorus levels (0.25; 0.35; 0.45 e $0.55 \%$ ) were used. The dicalcium phosphate was used as phosphorus source. The diets were fed to the fishes three times a day to apparent satiation, during 46 days. No significant effect of dietary available phosphorus on hepatosomatic index, survival rate and carcass water and protein contents were observed. The increase of available phosphorus levels in the diet promoted linear increase of average weight gain and phosphorus excretion, and content of ash in carcass and ashes, calcium. There was a quadratic effect of dietary available phosphorus on feed intake, feed conversion ratio and protein efficiency ratio and the best values were obtained with $0.37,0.48$ and $0.48 \%$, respectively. Dietary requirement of available phosphorus for Nile tilapia from 35 to $100 \mathrm{~g}$ is $0.48 \%(0.53 \% \mathrm{DM})$.
\end{abstract}

Key Words: bones, fish, mineral, performance

\section{Introdução}

O fósforo, um macromineral essencial para o adequado crescimento e a reprodução dos peixes, é um importante constituinte estrutural do tecido esquelético (Roy \& Lall, 2003) e se encontra distribuído em todas as células do organismo (Lovell, 1988). É exigido em grandes quantidades na dieta e, ainda que os peixes possam utilizar o fósforo da água, a eficiência dessa absorção é baixa (NRC, 1993).
A deficiência de fósforo prejudica a mineralização dos ossos (Furuya et al., 2001a), a redução na taxa de crescimento e a deposição de minerais na carcaça e nos ossos (Rodehutscord \& Pfeffer, 1995; Dougall et al., 1996; Hardy \& Glatin III, 2002; Lall, 2002). Peixes alimentados com dietas deficientes em fósforo apresentam deformidades em diversas regiões do corpo (Cheng et al., 2005), decorrentes da baixa mineralização, que resulta em ossos porosos e aumenta os casos de deformidade (Roy \& Lall, 2003; Sugiura et al., 2004). O aumento na deposição de lipídios na carcaça 
também tem sido observado, provavelmente em virtude da alteração nos níveis plasmáticos de fosfatase alcalina e de enzimas envolvidas na gliconeogênese no fígado (Baeverfjord et al., 1998; Zhang et al., 2006; Yang et al., 2006).

A ração é a principal fonte de fósforo em criações intensivas, pois a concentração desse mineral é baixa, tanto em águas doces quanto em águas marinhas. Assim, é importante o adequado balanceamento de minerais para minimizar as perdas urinária e fecal para reduzir a possibilidade de eutrofização (Richie \& Brown, 1996), que pode comprometer a qualidade da água e as características organolépticas da carcaça dos peixes (Van Der Ploeg \& Boyd, 1991; English et al., 1993).

Nos alimentos de origem vegetal, a disponibilidade do fósforo é baixa, uma vez que esse mineral se encontra na forma de fitato, não disponível a animais não-ruminantes (Sugiura et al., 1998). Como nos peixes a presença da enzima fitase é desprezível (Hardy, 1998), a ração é a principal fonte de fósforo para esses animais, uma vez que o fósforo absorvido da água é insuficiente para atender suas exigências. Assim, o fosfato bicálcico é a principal fonte inorgânica de fósforo em rações para peixes, principalmente quando essas rações contêm elevadas proporções de alimentos de origem vegetal.

Ainda são poucos os trabalhos realizados no Brasil para determinar as exigências de fósforo por tilápias-donilo em criação intensiva nas diferentes fases de criação. Esses estudos são necessários para melhorar o desempenho produtivo de forma economicamente viável, por meio do adequado crescimento dos peixes e da manutenção da qualidade de carcaça e da qualidade da água, permitindo a criação sustentável de tilápias em sistemas intensivos.

Este trabalho foi realizado com o objetivo de determinar a exigência de fósforo disponível para tilápias-do-nilo (35 a 100 g) em tanques de recirculação.

\section{Material e Métodos}

O experimento foi realizado no Laboratório de Aqüicultura da Universidade Estadual de Maringá - UEM, Maringá, Paraná, durante 46 dias, no período de janeiro e fevereiro de 2006.

Foram utilizados 144 peixes com peso vivo inicial de $35,33 \pm 0,66 \mathrm{~g}$, distribuídos em delineamento de blocos ao acaso, com quatro tratamentos e três repetições. Os peixes foram alojados em 12 gaiolas cilíndricas (cada uma com volume útil de $200 \mathrm{~L}$ ), distribuídas em três tanques de fibrocimento $(1.000 \mathrm{~L})$, cada um com uma unidade experimental de um tratamento. Cada tanque foi mantido com sistema de recirculação de água (7.000 L/dia) e aeração individual por meio de pedra porosa acoplada a um soprador central. O oxigênio dissolvido foi mantido entre 4 e $6 \mathrm{mg} / \mathrm{L}$ e a temperatura entre 28 e $30^{\circ} \mathrm{C}$ por meio de aquecedores ligados a um termostato inserido no biofiltro central.

Foram avaliadas quatro dietas elaboradas para conter aproximadamente $2.980 \mathrm{kcal}$ de energia digestível (ED)/kg de ração, 29\% de proteína bruta e 0,25; 0,35; 0,45 e 0,55\% de fósforo disponível (Tabela 1).

Todos os ingredientes foram triturados em moinho martelo elétrico até atingirem diâmetro igual ou inferior a 0,36 mm. Em seguida, as rações foram extrusadas na Fazenda Experimental de Iguatemi, FEI, de forma a apresentarem grânulos com diâmetro médio de 3,5 mm.

O arraçoamento foi realizado manualmente três vezes ao dia até a saciedade aparente. Realizou-se semanalmente o sifonamento manual dos tanques para retirada das fezes acumuladas no fundo dos tanques.

Todos os peixes foram pesados no início e ao final do experimento. A taxa de eficiência protéica foi calculada de acordo com a expressão descrita por Jauncey \& Ross

Tabela 1 - Composição das dietas experimentais

\begin{tabular}{|c|c|c|c|c|}
\hline \multirow[b]{2}{*}{ Ingrediente } & \multicolumn{4}{|c|}{ Fósforo disponível (\%) } \\
\hline & 0,25 & 0,35 & 0,45 & 0,55 \\
\hline Quirera de arroz & 6,00 & 6,00 & 6,00 & 6,00 \\
\hline Farelo de soja & 44,30 & 44,20 & 44,30 & 44,30 \\
\hline Milho em grão & 21,38 & 21,13 & 20,85 & 20,38 \\
\hline Trigo farelo & 20,00 & 20,00 & 20,00 & 20,00 \\
\hline Farinha de peixe & 5,00 & 5,00 & 5,00 & 5,00 \\
\hline Calcário calcítico & 1,20 & 0,85 & 0,33 & 0,00 \\
\hline Fosfato bicálcico & 0,00 & 0,60 & 1,40 & 2,20 \\
\hline Óleo de soja & 1,00 & 1,00 & 1,00 & 1,00 \\
\hline DL-metionina & 0,15 & 0,15 & 0,15 & 0,15 \\
\hline L-treonina & 0,10 & 0,10 & 0,10 & 0,10 \\
\hline $\begin{array}{l}\text { Suplemento mineral e } \\
\text { vitamínico }\end{array}$ & 0,50 & 0,50 & 0,50 & 0,50 \\
\hline Vitamina $C^{2}$ & 0,05 & 0,05 & 0,05 & 0,05 \\
\hline Sal & 0,35 & 0,35 & 0,35 & 0,35 \\
\hline $\mathrm{BHT}^{3}$ & 0,02 & 0,02 & 0,02 & 0,02 \\
\hline \multicolumn{5}{|l|}{ Valor determinado } \\
\hline Matéria seca $(\%)^{4}$ & 90,22 & 90,38 & 90,33 & 90,47 \\
\hline Energia digestível $(\mathrm{kcal} / \mathrm{kg})^{4}$ & 3.095 & 3.089 & 3.174 & 3.028 \\
\hline Proteína bruta $(\%)^{4}$ & 29,08 & 29,01 & 29,05 & 29,06 \\
\hline Fibra bruta $(\%)^{4}$ & 4,05 & 4,16 & 4,15 & 4,14 \\
\hline Extrato etéreo $(\%)^{4}$ & 4,42 & 4,69 & 4,78 & 4,95 \\
\hline Cálcio $(\%)^{4}$ & 0,90 & 0,91 & 0,92 & 0,95 \\
\hline Fósforo total $(\%)^{4}$ & 0,54 & 0,77 & 0,97 & 1,15 \\
\hline Fósforo disponível (\%) ${ }^{4}$ & 0,24 & 0,35 & 0,46 & 0,57 \\
\hline \multicolumn{5}{|c|}{ 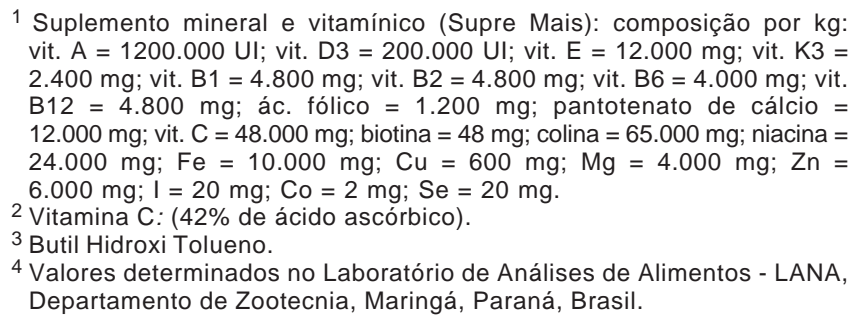 } \\
\hline
\end{tabular}


(1982). Para análise da retenção de cálcio e fósforo nos ossos, foram coletados os ossos da cabeça, segundo a metodologia descrita por Furuya et al. (2001b). Ao final do experimento, os ossos foram triturados em moinho bola e desengordurados com éter de petróleo durante 24 horas.

A excreção de fósforo foi determinada considerando os valores de fósforo total e de fósforo disponível em cada dieta. A disponibilidade do fósforo pelos peixes alimentados com cada dieta foi determinada de acordo com a expressão descrita por Nose (1960):

$$
\mathrm{CDA}=100-\left[100 .\left(\frac{\mathrm{\% I}_{\mathrm{d}}}{\mathrm{OI}_{\mathrm{f}}}\right) \cdot\left(\frac{\mathrm{\% P}_{\mathrm{f}}}{\mathrm{\% P}_{\mathrm{d}}}\right)\right]
$$

em que: $\mathrm{CDA}$ = coeficiente de digestibilidade aparente (\%); $\% \mathrm{I}_{\mathrm{d}} \mathrm{e} \% \mathrm{I}_{\mathrm{f}}=\%$ indicador na dieta e nas fezes, respectivamente; e $\% \mathrm{P}_{\mathrm{f}} \mathrm{e} \% \mathrm{P}_{\mathrm{d}}=\%$ de fósforo nas fezes ena dieta, respectivamente.

O óxido de cromo foi utilizado como indicador ( $0,1 \%$ da dieta). Para confecção das rações, após pesagem e homogeneização dos ingredientes, foi pulverizada água $\left(55^{\circ} \mathrm{C}\right)$ na proporção de $12 \%$ de seu peso total. Em seguida, as rações foram peletizadas em moinho de carne e desidratadas em estufa de ventilação forçada $\left(55^{\circ} \mathrm{C}\right)$ durante 18 horas (Pezzato el al., 2002). A coleta de fezes foi realizada diariamente às 8 e $17 \mathrm{~h}$ durante sete dias para formação de um pool, considerado repetição. Para cada ração analisada, foram coletados três pools de fezes.

A troca das dietas foi realizada em intervalos de cinco dias para adaptação. O material coletado foi desidratado em estufa de ventilação forçada a temperatura de $55^{\circ} \mathrm{C}$ durante 24 horas. Após secagem, o material foi triturado em moinho martelo, identificado e armazenado em refrigerador para posterior análise.

Os peixes foram arraçoados a cada duas horas, das 8 às $17 \mathrm{~h}$. O arraçoamento foi feito manualmente e à vontade até saciedade aparente, quando não houve mais captura dos grânulos fornecidos durante seu deslocamento da superfície até o fundo dos aquários de alimentação.

As análises químico-bromatológicas das dietas, das carcaças e dos ossos foram realizadas no Laboratório de Análise de Alimentos do Departamento de Zootecnia da Universidade Estadual de Maringá - UEM, segundo metodologia descrita por Silva (1990).

Os dados foram submetidos a análises de variância e regressão polinomial pelo programa SAEG (UFV, 1992).

\section{Resultados e Discussão}

Não foram observados efeitos significativos dos níveis de fósforo disponível sobre o índice hepatossomático, a
Tabela 2 - Desempenho de tilápias-do-nilo alimentadas com dietas contendo níveis crescentes de fósforo disponível

\begin{tabular}{lrrrrr}
\hline & \multicolumn{3}{c}{ Fósforo disponível (\%) } & \multirow{2}{*}{ CV } \\
\cline { 2 - 5 } Variável & 0,25 & 0,35 & 0,45 & 0,55 & \\
\hline Peso inicial (g) & 35,64 & 35,08 & 35,25 & 35,36 & 2,07 \\
Peso final (g) & 99,53 & 101,38 & 99,94 & 111,74 & 4,50 \\
Ganho de peso (g) & 63,89 & 66,30 & 64,69 & 76,39 & 6,99 \\
Consumo de ração $^{2}$ & 107,36 & 102,50 & 100,71 & 117,70 & 3,54 \\
Conversão alimentar $^{2}$ & 1,69 & 1,55 & 1,58 & 1,60 & 3,64 \\
Taxa de eficiência $^{2,05}$ & 2,23 & 2,37 & 2,32 & 10,30 \\
protéica & & & & & \\
Índice hepatossomático $^{2}$ & 1,50 & 1,60 & 1,36 & 1,49 & 9,32 \\
\hline
\end{tabular}

${ }^{1}$ Efeito linear: ganho de peso $(P<0,05):\left(\hat{Y}=52,7410+40,7267 X ; R^{2}=0,94\right)$

2 Efeito quadrático $(P<0,05)$ : consumo de ração ( $\hat{Y}=179,5630-430,218 X$ $\left.+579,2880 X^{2} ; R^{2}=0,78\right) ;$ conversão alimentar $(P<0,05)(\hat{Y}=2,4095-$ $\left.3,8827 X+4,0397 X^{2} ; R^{2}=0,76\right) ;$ taxa de eficiência $(P<0,05)(\hat{Y}=0,9896$ $\left.+5,6575 X-5,8546 X^{2} ; R^{2}=0,68\right)$.

taxa de sobrevivência e os teores de água e proteína bruta na carcaça (Tabela 2). Não houve mortalidade dos peixes durante o período experimental. Durante a coleta de ossos para análise de minerais, não foram observados sinais de deficiência de fósforo, como anormalidades externas ou deformidades ósseas.

Pela análise de regressão, o ganho de peso aumentou linearmente $(\mathrm{P}<0,05)$ de acordo com os níveis de fósforo disponível na dieta. Observou-se efeito quadrático das dietas sobre o consumo de ração, a conversão alimentar e a taxa de eficiência protéica, que foram melhores nos níveis de 0,$37 ; 0,48$ e $0,48 \%$ de fósforo disponível, respectivamente.

Na análise da conversão alimentar, que inclui o consumo de ração e o ganho de peso, a exigência de fósforo disponível determinada para tilápias-do-nilo (35 a 100 g) foi de $0,48 \%$, ou $0,55 \%$ com base na matéria seca. O valor obtido neste estudo foi inferior aos descritos por Watanabe et al. (1980) para tilápias-do-nilo (1\%), Asgard \& Shearer (1997) para o salmão-do-atlântico (1\%), Borlongan \& Satoh (2001) para “milkfish” (0,85\%), Oliva-Teles \& Pimentel-Rodrigues (2004) para "sea bream” (0,75\%) e Zhang et al. (2006) para "sea bass" $(0,86 \%)$, valores determinados com base na matéria seca.

A exigência de fósforo disponível determinada neste estudo, com base na matéria seca, quando avaliados o crescimento e a eficiência de utilização de nutrientes, encontra-se na faixa (0,5-0,6\%) determinada para as espécies tilápia-azul (Robinson et al., 1987), "sunshine bass" (Brown et al., 1993) e "striped bass" (Doughall et al., 1996) e foi superior à exigência estimada por Wilson et al. (1988), de $0,4 \%$ para bagre-do-canal.

As diferenças entre os valores estimados neste estudo e os encontrados na literatura podem estar relacionadas ao tipo de variável utilizada para determinar a exigência. Zhang 
et al. (2006) demonstraram que a exigência de fósforo para máxima retenção de fósforo nos ossos em “seabass” japonês foi aproximadamente 33\% maior que a de fósforo para máximo crescimento.

Ainda que o efeito do tamanho dos peixes não tenha sido especificamente avaliado, sabe-se que a composição corporal em minerais varia com o aumento do peso dos peixes (Ronsholdt, 1995). Os pesos inicial e final dos peixes utilizados nos experimentos para determinar as exigências de fósforo têm variado bastante entre e dentro de espécies. Shearer (1995) sugeriu que a exigência de fósforo para peixes juvenis é maior que para alevinos e decresce na fase adulta. Confirmando parte dessa hipótese, as exigências de fósforo obtidas neste estudo para juvenis foram superiores às determinadas por Furuya et al. (2008) para alevinos de tilápia-do-nilo $(0,45 \%$, com base na matéria natural).

A análise estatística para avaliar a relação dose-resposta é provavelmente o fator que mais influencia a variação nos estudos de exigências nutricionais. Baker (1986) discutiu os métodos para analisar estatisticamente os experimentos de dose-resposta e concluiu que em muitos casos as diferenças decorreram unicamente da análise estatística utilizada. Ainda que a ANOVA seguida da comparação por algum teste de média seja o método mais utilizado em estudos objetivando a determinação da exigência de fósforo, não é adequada quando a variável independente é quantitativa. Além disso, a aplicação do teste de média geralmente resulta em valor inferior ao realmente exigido pelos animais. De acordo com Asgard \& Shearer (1997), a análise de regressão permite extrapolar dados entre os pontos avaliados e consiste na forma objetiva mais adequada para estimar as exigências.

De modo geral, o desempenho produtivo dos peixes que receberam a dieta com $0,25 \%$ de fósforo disponível foi inferior ao obtido com os demais tratamentos. Esse menor desempenho provavelmente resultou da insuficiência de fósforo disponível para o crescimento, uma vez que o fósforo foi utilizado para outras funções fisiológicas de manutenção.

Com o aumento nos níveis de fósforo disponível, verificou-se efeito quadrático $(\mathrm{P}<0,05)$ no teor de extrato etéreo na carcaça (Tabela 3), que foi menor no nível de $0,44 \%$ de fósforo disponível. $\mathrm{O}$ aumento nos teores de fósforo disponível na dieta resultou em aumento linear $(\mathrm{P}<0,05)$ sobre os teores de cinzas na carcaça e cinzas, cálcio e fósforo nos ossos.

A menor deposição de gordura na carcaça nos peixes alimentados com a dieta contendo $0,44 \%$ de fósforo disponível confirma os resultados obtidos por Sakamoto \& Yone
Tabela 3 - Composição corporal e mineral nos ossos de tilápiasdo-nilo alimentadas com dietas contendo níveis crescentes de fósforo disponível

\begin{tabular}{|c|c|c|c|c|c|}
\hline \multirow[b]{2}{*}{ Variável } & \multicolumn{4}{|c|}{ Fósforo disponível (\%) } & \multirow[t]{2}{*}{ CV } \\
\hline & 0,25 & 0,35 & 0,45 & 0,55 & \\
\hline \multicolumn{6}{|l|}{$\begin{array}{l}\text { Composição } \\
\text { corporal (\%) }\end{array}$} \\
\hline Água & 72,96 & 73,29 & 75,55 & 74,40 & 1,45 \\
\hline Proteína bruta & 16,71 & 16,68 & 16,08 & 16,39 & 0,91 \\
\hline Extrato etéreo ${ }^{2}$ & 7,14 & 6,71 & 5,68 & 6,63 & 3,42 \\
\hline Cinzas $^{1}$ & 4,16 & 4,18 & 4,79 & 5,14 & 25,40 \\
\hline \multicolumn{6}{|l|}{ Ossos } \\
\hline Cinzas & 40,64 & 47,43 & 52,48 & 56,17 & 1,65 \\
\hline Cálcio ${ }^{1}$ & 15,30 & 18,64 & 19,51 & 19,42 & 10,09 \\
\hline Fósforo ${ }^{1}$ & 5,94 & 7,00 & 7,59 & 8,26 & 7,77 \\
\hline \multicolumn{6}{|c|}{$\begin{array}{l}{ }^{1} \text { Efeito linear: cinzas }(P<0,05)\left(\hat{Y}=2,1359+6,5735 X ; R^{2}=0,87\right) \text {; cálcio } \\
\text { nos ossos }(P<0,05)\left(\hat{Y}=12,9176+13,2468 X ; R^{2}=0,74\right) \text {; fósforo nos } \\
\text { ossos }(P<0,05)\left(\hat{Y}=4,1744+7,5563 X ; R^{2}=0,98\right) \text {. } \\
{ }^{2} \text { Efeito quadrático: extrato etéreo }(P<0,05)(\hat{Y}=12,6828-30,2927 X+ \\
\left.34,6404 X^{2} ; R^{2}=0,71\right) \text {. }\end{array}$} \\
\hline
\end{tabular}

(1978) com “red sea bream”, Eya \& Lovell (1996) com bagredo-canal e Roy \& Lall (2003), com a truta arco-íris. Esses autores observaram redução no teor de lipídios na carcaça quando os peixes foram alimentados com dietas com nível adequado de fósforo. A redução no teor de gordura está relacionada à inibição do ciclo do ácido cítrico e ao acúmulo de acetil-CoA.

Neste estudo, a menor utilização de proteína pelos peixes alimentados com a dieta com $0,25 \%$ de fósforo disponível possivelmente está associada à inibição da ß-oxidação dos ácidos graxos, que resultou em menor utilização dos lipídios como fonte de energia e em utilização de proteína como fonte alternativa de energia (Roy \& Lall, 2003).

Zhang et al. (2006) relataram que a exigência de fósforo para máxima retenção de fósforo nos ossos em "seabass" japonês foi aproximadamente 33\% maior que a exigência desse mineral para máximo crescimento. Neste estudo, não foi observado ponto de máxima retenção de minerais, cálcio e fósforo nos ossos, portanto, níveis superiores de fósforo disponível devem ser avaliados para estimativa das exigências desse mineral com base em valores de retenção de minerais nos ossos. No entanto, de acordo com Zhang et al. (2006), o fósforo presente nos ossos, nas escamas e em outros tecidos dos peixes possui capacidade tamponante em situações de mudança do suprimento de fósforo. Assim, a deposição de fósforo não precisa ocorrer no nível máximo para maior ganho de peso.

A mineralização óssea é variável representativa do nível de fósforo em tilápias-do-nilo. Em virtude de importância na formação da estrutura óssea, o aumento no teor 


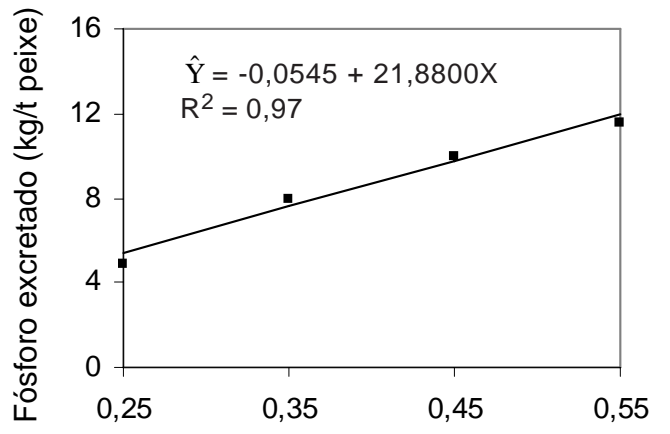

Fósforo disponível (\%)

Figura 1 - Excreção de fósforo por tilápias-do-nilo alimentadas com dietas com níveis crescentes de fósforo disponível.

de fósforo em dietas para peixes aumenta o conteúdo desse mineral nos ossos, elevando os teores de minerais e cálcio nos ossos, fato observado por Borlongan \& Satoh (2001), em estudo realizado com juvenis de "milkfish", e Zhang et al. (2006), em pesquisa com juvenis de "seabass".

A excreção de fósforo aumentou $(\mathrm{P}<0,05)$ de acordo com os níveis de fósforo na dieta (Figura 1), o que confirma os resultados obtidos por Oliva-Teles \& Pimentel-Rodrigues (2004).

De acordo com Borlongan \& Satoh (2001), o fósforo fecal é a principal forma de excreção de fósforo pelos peixes. Neste estudo, ainda que o ganho de peso pelos peixes tenha aumentado linearmente com o aumento nos níveis de fósforo disponível na dieta, a excreção de fósforo fecal por quilo de peixe produzido aumentou linearmente, comprovando a necessidade de não utilizar dietas com valores de fósforo disponível acima das exigências. Na prática, é comum utilizar dietas com valores de fósforo disponível acima das exigências, principalmente pelo fato de serem utilizadas fontes protéicas de origem animal com elevado teor de cinzas.

Em criação intensiva, o fósforo é um dos nutrientes mais poluentes. $\mathrm{O}$ excesso desse mineral pode provocar eutrofização e prejudicar a qualidade da água, o que altera as características sensoriais da carcaça dos peixes. Assim, a determinação da exigência mínima de fósforo é importante para reduzir possíveis impactos ambientais e garantir a sustentabilidade da produção de peixes.

\section{Conclusões}

A exigência de fósforo disponível para tilápias-do-nilo (35 a 100 g) é de 0,48\% (0,53\% na matéria seca).

\section{Literatura Citada}

ASGARD, T.; SHEARER K.D. Dietary phosphorus requeriment of juvenile Atlantic salmon, Salmo salar L. Aquaculture Nutrition, v.3, p.17-23, 1997.

BAKER, D.H. Problems and pitfalls in animal experiments designed to establish dietary requirements for essential nutrients. Journal of Nutrition, v.116, p.23-39, 1986.

BAEVERFJORD, G.; ASGARD, T.; SHEARER, K.D. Development and detection of phosphorus deficiency in Atlantic salmon, Salmo salar L., parr and post-smolts. Aquaculture Nutrition, v.4, p.1-11, 1998.

BORLONGAN, I.G.; SATOH, S. Dietary phosphorus requeriment of juvenile milkfish, Chanos chanos (Forsskal). Aquaculture Research, v.32, p.26-32, 2001.

BROWN, M.L.; JARAMILlO, F.; GATLIN, D.M. Dietary phosphorus requeriment of juvenile sunshine bass, Morone chrysops X M. saxatilis. Aquaculture, v.113, p.355-363, 1993.

CHENG, A.C.; WU, J.D.; YANG, S.D. et al. Dietary phosphorus requeriment of juvenile Malabar grouper (Epinephelus malabaricus). Journal of Fish Society Taiwan, v.32, p.4152, 2005.

DOUGALL, D.S.; WOODS, L.C.; DOUGLASS, L.W. et al. Dietary phosphorus requirements of juvenile striped bass, Morone saxatilis. Journal of World Aquaculture Society, v.27, p.8291, 1996.

ENGLISH, W.R.; SCHWEDLER, T.E.; DYCK, L.A. Aphanizomenon flos-aquae, a toxic blue green alga in commercial channel catfish, Ictalurus punctatus, ponds: a case history. Journal of Applied Aquaculture, v.3, p.195-209, 1993.

EYA, J.C.; LOVELL, R.T. Available phosphorus requirements of food-size channel "catfish" (Ictalurus punctatus) fed practical diets in ponds. Aquaculture, v.154, p.283-291, 1997, 1986.

FURUYA, W.M.; PEZZATO, L.E.; MIRANDA, E.C. et al. Coeficientes de digestibilidade aparente da energia e nutrientes de alguns ingredientes pela tilápia do Nilo, Oreochromis niloticus (L.) (linhagem tailandesa). Acta Scientiarum, v.23, n.2, p.465469, 2001a.

FURUYA, W.M.; GONÇALVES, G.S.; FURUYA, V.R.B. et al. Fitase na Alimentação da tilápia do Nilo (Oreochromis niloticus L.): desempenho e digestibilidade. Revista Brasileira de Zootecnia, v.30, n.3, p.924-929, 2001b.

FURUYA, W.M.; FUJII, K.M.; SANTOS L.D. et al. Exigência de fósforo para juvenis de tilápia do Nilo em sistema de recirculação. Revista Brasileira de Zootecnia, 2008. (no prelo)

HARDY, R.W.; GATLIN, D.M. Nutritional strategies to reduce nutrients losses in intensive aquaculture. In: SIMPOSIUM INTERNACIONAL DE NUTRICIÓN ACUÍCOLA, 6., 2002, Cancun. Memórias... Cancun: 2002. p.23-34.

HARDY, R.W. Phytase. Aquaculture Magazine, p.77-80, 1998.

JAUNCEY, K.; ROSS, B. A guide to tilapia feeds and feeding. Scotland: University Press, 1982. 111p.

LALL, S.P. The minerals. In: HALVER, J.E.; HARDY, R.W. (Eds). Fish nutrition. 3.ed. San Diego: Academic Press, 2002. p.260308.

LOVELL, R.T. Nutrition and feeding of fish. New York: Van Nostrand Reinhold, 1988. 260p.

NOSE, T. On the digestion of food protein by gold-fish (Carassius auratus L.) and rainbow trout (Salmo irideus G.). Bulletin of Freshwater Fisheries Research Laboratory, v.10, p.11-22, 1960.

NATIONAL RESEARCH COUNCIL - NRC. Nutrient requirements of warmwater fishes and shellfishes. Washington, D.C. National Academy Press, 1993. 102p.

OLIVA-TELES, O.; PIMENTEL-RODRIGUES, A.M.P. Phosphorus requirements of European sea bass (Dicentrarchus labrax L.) juveniles. Aquaculture Research, v.35, p.636-642, 2004.

PEZZATO, L.E.; MIRANDA, E.C.; PEZZATO, A.C. et al. Digestibilidade aparente de ingredientes pela tilápia do Nilo 
(Oreochromis niloticus). Revista Brasileira de Zootecnia, v.31, n.4, p.1595-1604, 2002.

RICHIE, M.; BROWN, P.B. Availability of phosphorus from feedstuffs fed to rainbow trout, Oncorhynchus mykiss. Aquaculture, v.142, p.269-282, 1996.

ROBINSON, E.H.; LA BOMASCUS, D.; BROWN, P.B. et al. Dietary calcium and phosphorus requirements of Oreochromis aureus reared in calcium-free water. Aquaculture, v.64, p.264-276, 1987.

RODEHUTSCORD, M.; PFEFFER, E. Effects of supplemental microbial phytase on phosphorus digestibility and utilization in rainbow trout (Oncorhynchus mykiss). Water Science and Technology, v.31, n.10, p.143-147, 1995.

RONSHOLDT, B. Effect of fish size/age and feed composition on body composition and phosphorus content of rainbow trout, Oncorhynchus mykiss. Water Science and Technology, v.31, p.137-141, 1995.

ROY, P.K.; LALL, S.P. Dietary phosphorus requirement of juvenile haddock (Melanogrammus aeglefinus L.). Aquaculture, v.221, p.451-468, 2003.

SAKAMOTO, S.; YONE, Y. Effect of dietary phosphorus level on chemical composition of red sea bream. Bulletin of the Japanese Society of Scientific Fisheries, v.44, p.227-229, 1978.

SHEARER, K.D. The use of factorial modeling to determine the dietary requirements for essential elements in fishes. Aquaculture, v.133, p.57-72, 1995.

SILVA, D.J. Análise de alimentos (métodos químicos e biológicos). 2.ed. Viçosa, MG: Universidade Federal de Viçosa, 1990. 166p.
SUGIURA, S.H.; HARDY, R.W.; ROBERTS, R.J. The pathology of phosphorus deficiency in fish - a review. Journal of Fish Disease, v.27, p.255-265, 2004.

SUGIURA, S.H.; DONG, F.M.; RATHBONE, C.K. et al. Apparent protein digestibility and mineral availabilities in various feed ingredients for salmonid feeds. Aquaculture, v.159, p.177-202, 1998.

UNIVERSIDADE FEDERAL DE VIÇOSA - UFV. SAEG - Sistema de análises estatísticas e genéticas. Versão 5.0.Viçosa, MG: 1992. 59p.

Van der PLOEG, M.; BOYD, C.E. Geosmin production by cyanobacteria (blue green algae) in fish ponds at Auburn, Alabama. Journal of the World Aquaculture Society, v.22, p.207-216, 1991.

WATANABE, T.D.; TAKEUCHI T.; MURAKAMI A. et al. The availability to Tilapia nilotica of phosphorus in white fish meal. Bulletin of the Japanese Society of Scientific Fisheres, v.46, p.897-899, 1980.

WILSON, R.P.; ROBINSON, E.H.; GATLIN, D.M. et al. Dietary phosphorus requirement of channel catfish. Journal of Nutrition, v.112, p.1197-1202, 1988.

YANG, S.; LIN, T.; LIU, F. et al. Influence of dietary phosphorus levels on growth, metabolic response and body composition of juvenile silver perch (Bidyanus bidyanus). Aquaculture, v.253, p.592-601, 2006.

ZHANG, C.; MAI, K; AI, Q. et al. Dietary phosphorus requeriment of juvenile Japanese seabass, Lateolabrax japonicus. Aquaculture, v.255, p.201-209, 2006. 